\title{
Berberine reverses multidrug resistance in Candida albicans by hijacking the drug efflux pump Mdr1p
}

Tong, Yaojun; Zhang, Jingyu; Sun, Nuo; Wang, Xiang Ming; Wei, Qi; Zhang, Yu; Huang, Ren; Pu, Yingying; Dai, Huanqin; Ren, Biao

Total number of authors:

27

Published in:

Science Bulletin

Link to article, DOI:

10.1016/j.scib.2020.12.035

Publication date:

2021

Document Version

Publisher's PDF, also known as Version of record

Link back to DTU Orbit

Citation (APA):

Tong, Y., Zhang, J., Sun, N., Wang, X. M., Wei, Q., Zhang, Y., Huang, R., Pu, Y., Dai, H., Ren, B., Pei, G., Song, F., Zhu, G., Wang, X., Xia, X., Chen, X., Jiang, L., Wang, S., Ouyang, L., ... Alterovitz, G. (2021).

Berberine reverses multidrug resistance in Candida albicans by hijacking the drug efflux pump Mdr1p. Science Bulletin, 66(18), 1895-1905. https://doi.org/10.1016/j.scib.2020.12.035

\section{General rights}

Copyright and moral rights for the publications made accessible in the public portal are retained by the authors and/or other copyright owners and it is a condition of accessing publications that users recognise and abide by the legal requirements associated with these rights.

- Users may download and print one copy of any publication from the public portal for the purpose of private study or research.

- You may not further distribute the material or use it for any profit-making activity or commercial gain

- You may freely distribute the URL identifying the publication in the public portal 
Article

\title{
Berberine reverses multidrug resistance in Candida albicans by hijacking the drug efflux pump Mdr1p
}

\author{
Yaojun Tong a,b,i,1,*, Jingyu Zhang ${ }^{\mathrm{a}, 1}$, Nuo Sun ${ }^{\mathrm{d}, 1}$, Xiang-Ming Wang ${ }^{\mathrm{c}, 1}$, Qi Wei ${ }^{\mathrm{b}}$, Yu Zhang ${ }^{\mathrm{f}}$, Ren Huang ${ }^{\mathrm{f}}$, \\ Yingying Pu ${ }^{c}$, Huanqin Dai ${ }^{\mathrm{b}, \mathrm{h}}$, Biao Ren ${ }^{\mathrm{b}}$, Gang Pei ${ }^{\mathrm{b}}$, Fuhang Song ${ }^{\mathrm{b}}$, Guoliang Zhu ${ }^{\mathrm{a}}$, Xinye Wang ${ }^{\mathrm{a}}$, \\ Xuekui Xia $^{\mathrm{j}}$, Xiangyin Chen ${ }^{\mathrm{a}}$, Lan Jiang ${ }^{\mathrm{a}}$, Shenlin Wang ${ }^{\mathrm{a}}$, Liming Ouyang ${ }^{\mathrm{a}}$, Ning Xie ${ }^{\mathrm{k}}$, Buchang Zhang ${ }^{\mathrm{e}}$, \\ Yuanying Jiang $^{\mathrm{g}}$, Xueting Liu ${ }^{\mathrm{a}}$, Richard Calderone ${ }^{\mathrm{d}}$, Fan Bai ${ }^{\mathrm{c}, *}$, Lixin Zhang ${ }^{\mathrm{a}, *}$, Gil Alterovitz ${ }^{\mathrm{k}, \mathrm{l}}$ \\ a State Key Laboratory of Bioreactor Engineering and School of Biotechnology, East China University of Science and Technology, Shanghai 200237, China \\ ${ }^{\mathrm{b}}$ Chinese Academy of Sciences Key Laboratory of Pathogenic Microbiology and Immunology, Institute of Microbiology, Chinese Academy of Sciences, Beijing 100190, China \\ ${ }^{\mathrm{c}}$ Biomedical Pioneering Innovation Center (BIOPIC), School of Life Sciences, Peking University, Beijing 100871, China \\ ${ }^{\mathrm{d}}$ Georgetown University Medical Center, Department of Microbiology \& Immunology, Washington DC 20057, USA \\ ${ }^{\mathrm{e}}$ Institute of Health Sciences, School of Life Sciences, Anhui University, Hefei 230601, China \\ ${ }^{\mathrm{f}}$ Guangdong Provincial Key Laboratory of Laboratory Animals, Guangdong Laboratory Animals Monitoring Institute, Guangzhou 510663, China \\ ${ }^{g}$ Department of Pharmacology, Second Military Medical University, Shanghai 200433, China \\ ${ }^{\mathrm{h}}$ State Key Laboratory of Mycology, Institute of Microbiology, Chinese Academy of Sciences, Beijing 100101, China \\ ${ }^{i}$ The Novo Nordisk Foundation Center for Biosustainability, Technical University of Denmark, 2800 Kgs. Lyngby, Denmark \\ ${ }^{\mathrm{j}}$ Key Biosensor Laboratory of Shandong Province, Biology Institute, Qilu University of Technology (Shandong Academy of Sciences), Jinan 250013, China \\ ${ }^{\mathrm{k}}$ Brigham and Women's Hospital, Boston MA 02115, USA \\ ${ }^{1}$ National Artificial Intelligence Institute, U.S. Department of Veterans Affairs, Washington DC 20420, USA
}

\section{A R T I C L E I N F O}

\section{Article history:}

Received 30 July 2020

Received in revised form 13 September

2020

Accepted 24 December 2020

Available online 31 December 2020

\section{Keywords:}

Candida albicans

Berberine

Multidrug-resistance

Drug excretion transporter

Mitochondria

\begin{abstract}
A B S T R A C T
Clinical use of antimicrobials faces great challenges from the emergence of multidrug-resistant pathogens. The overexpression of drug efflux pumps is one of the major contributors to multidrug resistance (MDR). Reversing the function of drug efflux pumps is a promising approach to overcome MDR. In the life-threatening fungal pathogen Candida albicans, the major facilitator superfamily (MFS) transporter Mdr1p can excrete many structurally unrelated antifungals, leading to MDR. Here we report a counterintuitive case of reversing MDR in C. albicans by using a natural product berberine to hijack the overexpressed Mdr1p for its own importation. Moreover, we illustrate that the imported berberine accumulates in mitochondria and compromises the mitochondrial function by impairing mitochondrial membrane potential and mitochondrial Complex I. This results in the selective elimination of Mdr1p overexpressed C. albicans cells. Furthermore, we show that berberine treatment can prolong the mean survival time of mice with blood-borne dissemination of Mdr1p overexpressed multidrug-resistant candidiasis. This study provides a potential direction of novel anti-MDR drug discovery by screening for multidrug efflux pump converters.
\end{abstract}

(C) 2020 Science China Press. Published by Elsevier B.V. and Science China Press. This is an open access article under the CC BY-NC-ND license (http://creativecommons.org/licenses/by-nc-nd/4.0/).

\section{Introduction}

Considering the high mortality of fungal infections in immunocompromised patients and the limited number of effective and safe antifungal drugs, the development of new antifungals and/or antifungal therapeutics is critical [1]. Widespread and repeated use of current antifungals, particularly azoles, however, has led to the

\footnotetext{
* Corresponding authors.

E-mail addresses: yato@biosustain.dtu.dk (Y. Tong), fbai@pku.edu.cn (F. Bai), lxzhang@ecust.edu.cn (L. Zhang).

1 These authors contributed equally to this work.
}

rapid occurrence of antifungal resistance [2]. Current approaches for novel antifungals discovery are usually targeting essential fungal genes or metabolic pathways, which are very likely to generate drug resistance over time.

One major mechanism underlying fungal drug resistance is the overexpression of drug excretion transporters. There are two types of such transporters in the most commonly seen clinical fungal pathogen $C$. albicans. The $C$. albicans drug-resistance (CDR) transporters, like Cdr1p and Cdr2p, which belong to the ATP-binding cassette $(A B C)$ family, use ATP as their energy source for drug excretion [3]. The other type is the major facilitator superfamily (MFS) transporter, such as Mdr1p (also known as the benomyl/ 
methotrexate resistance protein). This superfamily is a drug $/ \mathrm{H}^{+}$ antiporter that uses the proton gradient across the cytoplasmic membrane for drug excretion [4-6]. Enhanced expression of MDR1 has been correlated with resistance to a variety of structurally unrelated compounds, such as fluconazole and cerulenin [7]. In theory, as a proton gradient drove drug $/ \mathrm{H}^{+}$antiporter, Mdr1p has the potential to work reversely, importing substrates while exporting $\mathrm{H}^{+}$. This could provide a novel opportunity for antifungals to fight against multidrug-resistant $C$. albicans.

Berberine is an alkaloid with a long history of medicinal application in traditional Chinese medicine that can be produced by many plant species, such as Coptis chinensis (Coptis, goldenthread), Hydrastis canadensis (goldenseal), and Berberis vulgaris (barberry). Berberine has demonstrated significant activities on antimicrobial [8], anti-tumor [9], anti-inflammatory [10], antidiabetes [11], lower-cholesterol [12], and compromisemitochondrial functions [13]. Recent studies indicated that fungal mitochondria might be a potential antifungal target due to the presence of unique DNA/proteins [14].

In this study, we described an unexpected association between the killing effect of berberine and the expression of Mdr1p in $C$. albicans. Instead of being excreted, berberine can hijack the overexpressed Mdr1p to facilitate its own accumulation. Berberine then compromises the function of mitochondria to selectively eliminate the Mdr1p overexpressed multidrug-resistant $C$. albicans.

\section{Materials and methods}

\subsection{Strains and growth conditions}

The complete list of strains used in this study is listed in Table S1 (online). Fungal strains are stored in 25\% glycerol at $-80^{\circ} \mathrm{C}$, while cell lines, ordered from the cell bank, Shanghai Institutes for Biological Sciences, are stored in liquid nitrogen.

RPMI 1640 (Invitrogen, Carlsbad, USA) is used according to the manufacturer's protocol. The Yeast Extract-Peptone-Dextrose (YPD) medium consisted of yeast extract $1 \%(\mathrm{w} / \mathrm{v})$, peptone $2 \%$ $(\mathrm{w} / \mathrm{v})$, and dextrose $2 \%(\mathrm{w} / \mathrm{v})$, with $2 \%(\mathrm{w} / \mathrm{v})$ agar to make a solid medium when needed.

\subsection{Antifungal agents and molecular probes}

All chemicals were used according to the manufacturers' directions. Fluconazole, itraconazole, sanguinarine hydrochloride, jatrorrhizine hydrochloride, palmatine hydrochloride, chelerythrine, and proflavine were purchased from the National Instisutes for Food and Drug Control, China (purity > 98\%). Berberine hydrochloride, cyclophosphamide, rhodamine 123, carbonyl cyanide-mchlorophenyl hydrazone (CCCP), propidium iodide (PI), and 2,7dichlorofluorescein diacetate (DCFH-DA) were purchased from Sigma-Aldrich, USA. Cerulenin was purchased from Alexis, Enzo Life Sciences, USA.

\subsection{Antifungal susceptibility assay}

Drug susceptibility testing was carried out as described previously [15] in flat-bottom, 96-well microtiter plates (Greiner, Pleidelsheim, Germany), using a broth microdilution protocol modified from the Clinical and Laboratory Standards Institute M27A methods [16]. The minimum inhibitory concentration (MIC) was determined as the concentration of drugs that inhibit fungal growth by $80 \%$ relative to the corresponding drug-free growth control by reading the optical density (OD, $A_{600 \mathrm{~nm}}$ ) using a FLUOstar OPTIMA microplate reader (BMG LABTECH, Ortenberg, Germany). Spot assay was performed as described previously [17]. A total of
$10 \mu \mathrm{L}$ samples of ten-fold serial dilutions of cells, suspended in phosphate-buffered saline (PBS), were spotted onto YPD plates in the absence (control) or the presence of tested drugs. Photos were taken after a $48 \mathrm{~h}$ incubation at $30^{\circ} \mathrm{C}$. For non-glucose utilization, glucose in yeast extract-peptone agar was replaced with $2 \%$ of citrate, glycerol, lactate, or ethanol.

\subsection{Berberine accumulation and release assay}

All C. albicans strains were grown at $30{ }^{\circ} \mathrm{C}$ overnight in YPD medium and washed twice with PBS. Cells were resuspended in PBS with approximately $5 \times 10^{7}$ cells $/ \mathrm{mL}$ (determined by hemocytometer counting). Berberine $(32 \mu \mathrm{g} / \mathrm{mL}$ ) was added to each sample for incubation at $30{ }^{\circ} \mathrm{C}$. For a $90 \mathrm{~min}$ accumulation assay, $1 \mathrm{~mL}$ of each sample was taken every $10 \mathrm{~min}$ and the supernatant was carefully removed by a pipette after $1 \mathrm{~min}$ of centrifugation at top speed, and then the cell pellets were resuspended in $1 \mathrm{~mL}$ PBS. For a $60 \mathrm{~min}$ release assay, $10 \mathrm{~mL}$ of each sample at the time point of $90 \mathrm{~min}$ is centrifuged for $5 \mathrm{~min}$ at $5000 \mathrm{~g}$, washed once, and then resuspended in $10 \mathrm{~mL}$ of PBS. The sampling procedure was similar to the accumulation assay. A total of $150 \mu \mathrm{L}$ samples were transferred into black 96-well microplates with the clear bottom (Greiner) for fluorescence measurements. Fluorescence measurements of berberine are performed with a BioTek $^{\mathrm{TM}}$ Synergy $^{\mathrm{TM}} \mathrm{Mx}$ Monochromator-Based MultiMode Reader (Thermo Fisher Scientific, Waltham, USA) at $360 \mathrm{~nm}$ excitation/520 nm emission wavelengths.

\subsection{Accumulation of berberine influenced by CCCP}

To investigate the influence of the proton gradient, a final concentration of $20 \mu \mathrm{g} / \mathrm{mL}$ CCCP was added to the samples $30 \mathrm{~min}$ before the start of accumulation or release assays. Samples were shaken at $200 \mathrm{r} / \mathrm{min}\left(30^{\circ} \mathrm{C}\right)$. After incubation, samples were washed with PBS to remove CCCP, then the berberine accumulation assay was carried out as described above.

\section{6. $\mathrm{pH}$-dependent accumulation of berberine}

To investigate the influence of $\mathrm{pH}$, cells were incubated in RPMI 1640 media adjusted to $\mathrm{pH} 4.0,5.0,5.5,6.0,6.5,7.0,7.5,8.0$, and 8.5 and treated with berberine. The berberine accumulation assay is carried out as described above.

\subsection{RNA preparation, sequencing, and transcriptome analysis}

Strains were incubated for $16 \mathrm{~h}$ at $30{ }^{\circ} \mathrm{C}$ in RPMI 1640 medium with shaking with $(32 \mu \mathrm{g} / \mathrm{mL})$ or without berberine. Two volumes of RNAprotect Reagent (Qiagen, Hilden, Germany) were added into the cultures according to the manufacturer's protocol. Cells were harvested, washed twice, and then resuspended into PBS. The cells were then lysed by lysozyme $\left(400 \mu \mathrm{g} / \mathrm{mL}\right.$, Ready-Lyse ${ }^{\mathrm{TM}}$ Lysozyme Solution, Epicenter). Total RNA was purified by RNeasy Mini Kit (Qiagen). Ribosomal RNA was removed by RiboMinus Transcriptome Isolation Kit (Invitrogen) and mRNA is cleaned up using RNeasy Mini Spin columns (Qiagen). The resulting mRNA was used for library construction for RNA-seq using NEBNext mRNA Library Prep Reagent set for Illumina (NEB, Ipswich, USA). Briefly, mRNA was fragmented to the desired length and reverse transcribed into the first-strand cDNA. The single-strand cDNA was used for synthesizing double-strand DNA followed by end repair, dA-tailing, adaptor ligation, and PCR amplification. The library was tested by length determination and quantitative PCR quantification. These constructed libraries were then sequenced by the Illumina platform by paired-end chemistry. 
RNA reads were aligned to the C. albicans SC5314 assembly using Tophat [18] and quantified with HTseq [19]. The raw read counts were normalized with DESeq2 [20] to estimate gene expression and identify differential gene expression. Differential gene expression was identified using the threshold of the parametric $P<0.05$ and a fold change of at least 2 and the false discovery rate $(\mathrm{FDR})<0.2$. Gene ontology analysis was performed at the Candida genome database (CGD, www.candidagenome.org) and FungiFun2 (https://elbe.hki-jena.de/fungifun/). Enrichment maps were constructed with Cytoscape 2.8 .3 (http://www.cytoscape.org) and the Enrichment Map v1.2 plug-in using the default settings (http://www.baderlab.org/Software).

\subsection{Assay of the reactive oxygen species (ROS) measurement}

As previously described [21], intracellular ROS production was detected by staining cells with the ROS-sensitive fluorescent dye DCFH-DA (2,7-dichlorofluorescein diacetate; Sigma, St. Louis, USA). Cells from $25 \mathrm{~mL}$ cultures grown at $30{ }^{\circ} \mathrm{C}$ overnight in YPD medium were collected and washed twice with PBS. The pellets were suspended to $10^{6}$ cells in $10 \mathrm{~mL}$ of PBS plus $2 \%$ glucose and treated with or without $10 \mu \mathrm{mol} / \mathrm{L}$ DCFH-DA for $30 \mathrm{~min}$ at $37{ }^{\circ} \mathrm{C}$ in dark. Cells from each sample were collected and washed twice with PBS after staining. The cells were resuspended with PBS plus $2 \%$ glucose and treated with berberine at the indicated concentrations for $60 \mathrm{~min} 30^{\circ} \mathrm{C}$. The fluorescent intensity was measured using a FACScan flow cytometer (Becton Dickinson, San Jose, USA). PI was added to each sample to detect dead cells. The mean fluorescence for ROS was quantified only in live cells.

\subsection{Assay of protoplast and mitochondrial preparations}

Cells were grown in $250 \mathrm{~mL}$ of YPD broth overnight at $30^{\circ} \mathrm{C}$, then washed and resuspended in RPMI 1640 medium. After incubation with or without $20 \mu \mathrm{g} / \mathrm{mL}$ berberine for $1 \mathrm{~h}$, cells were harvested by centrifugation ( $5000 \mathrm{r} / \mathrm{min}$ for $10 \mathrm{~min}$ ) and washed with $50 \mathrm{~mL}$ of cold water and buffer A (1 mol/L sorbitol, $10 \mathrm{mmol} / \mathrm{L}$ $\mathrm{MgCl}_{2}$, and $50 \mathrm{mmol} / \mathrm{L}$ Tris- $\mathrm{HCl}, \mathrm{pH}$ 7.8). Protoplasts were made by digesting the cell wall with Zymolyase $20 \mathrm{~T}$ for $1 \mathrm{~h}$ at $30^{\circ} \mathrm{C}$. The mitochondrial fraction was obtained by Percoll-densitygradient centrifugation as described previously [21], and suspended in $1 \mathrm{~mL}$ of buffer $\mathrm{D}(0.6 \mathrm{~mol} / \mathrm{L}$ mannitol, $10 \mathrm{mmol} / \mathrm{L}$ Tris$\mathrm{HCl}, \mathrm{pH}$ 7.0). The protein content was determined by the Biuret method.

\subsection{Assay for the measurement of mitochondrial membrane potential}

The mitochondrial membrane potential was determined by staining cells with rhodamine 123 [22]. Cells from $25 \mathrm{~mL}$ cultures grown at $30{ }^{\circ} \mathrm{C}$ overnight in YPD medium were collected and washed twice with RPMI 1640 medium. The pellets were resuspended in RPMI 1640 medium to $10^{6}$ cells $/ \mathrm{mL}$. Berberine was added at the indicated concentrations. After $60 \mathrm{~min}$ incubation, the samples were treated with or without $10 \mu \mathrm{g} / \mathrm{mL}$ rhodamine 123 for $15 \mathrm{~min}$ at $37{ }^{\circ} \mathrm{C}$ in dark. Cell fluorescence in the absence of rhodamine 123 was used to verify that background fluorescence is similar among strains. Cells from each sample were collected and washed twice with PBS after staining. Fluorescence was measured using a FACScan flow cytometer (Becton Dickinson).

\subsection{Assay for the oxygen consumption rate}

Oxygen consumption was measured polarographically using a Clark-type electrode (Hansatech Instruments, Norfolk, UK). Cells were grown overnight at $30{ }^{\circ} \mathrm{C}$ in $20 \mathrm{~mL}$ of YPD broth and diluted in fresh YPD broth the next day for an additional $4 \mathrm{~h}$ until exponen- tial growth was achieved. Cells were then centrifuged, washed with PBS, resuspended in RPMI 1640, and then treated with 10 $\mu \mathrm{g} / \mathrm{mL}$ berberine for $2 \mathrm{~h}$. Cells were collected, washed with PBS, and resuspended in $2 \mathrm{~mL}$ of YPD broth before loading into a sealed $1.5 \mathrm{~mL}$ glass chamber. The oxygen concentration in the chamber was monitored over a 5-10 min period. The respiratory rate was calculated as the consumption of oxygen per min per $\mathrm{mL}$ of cell suspension normalized by $A_{600 n m}$ value.

\subsection{Complex I (nicotinamide adenine dinucleotide hydrogen (NADH): ubiquinone oxidoreductase) activity assay}

Crude mitochondrial preparations were first treated with two cycles of freeze-thawing in a hypotonic solution $(25 \mathrm{mmol} / \mathrm{L}$ $\mathrm{K}_{2} \mathrm{HPO}_{4}$, pH 7.2, $5 \mathrm{mmol} / \mathrm{L} \mathrm{MgCl}_{2}$ ), followed by a hypotonic shock in $\mathrm{H}_{2} \mathrm{O}$. A total of $20 \mu \mathrm{g}$ of mitochondrial protein from each sample was used to measure complex I enzymatic activity. Mitochondria in $0.8 \mathrm{~mL}$ of $\mathrm{H}_{2} \mathrm{O}$ were incubated for $2 \mathrm{~min}$ at $37^{\circ} \mathrm{C}$ and then mixed

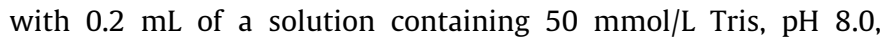
$5 \mathrm{mg} / \mathrm{mL}$ bovine serum albumin (BSA), $0.24 \mathrm{mmol} / \mathrm{L} \mathrm{KCN}$, $4 \mu \mathrm{mol} / \mathrm{L}$ antimycin $\mathrm{A}$, and $0.8 \mathrm{mmol} / \mathrm{L} \mathrm{NADH}$ (substrate of Complex I). The reaction was initiated by introducing an electron acceptor, $50 \mu \mathrm{mol} / \mathrm{L}$ 2,3-dimethoxy-5-methyl-6-n-decyl-1,4-benzo quinone (DB). Enzyme activity was followed as a decrease in absorbance of NADH at $340 \mathrm{~nm}$ minus that at $380 \mathrm{~nm}$.

\subsection{Relative quantification of differentially expressed genes by quantitative real-time PCR ( $q R T-P C R)$}

All primers used in this study for qRT-PCR are listed in Table S2 online. RNA isolation, cDNA synthesis, and PCR amplification were carried out as described previously [23]. Triplicate independent qRT-PCRs were performed using the LightCycler System (Roche, Basel, Switzerland). The change in fluorescence of SYBR Green I in every cycle was monitored by the system software, and the threshold cycle $(\mathrm{Ct})$ was measured. 18S rDNA was used as an internal control, and the relative gene expression level was calculated using the formula $2^{-\Delta \Delta C t}$.

\subsection{Murine model of systemic infection and drug treatment}

Mice related experiments were reviewed and approved by IACUC of Guangdong Laboratory Animal Monitoring Institute following the Guide for the Care and Use of Laboratory Animals under the license of IACUC2012006. Specific-pathogen-free female ICR (Crl: CD-1) mice (female, white, about 20-22 g) were used throughout the experiment, and the experiments were carried out as described previously [15]. Before infection, mice were rendered neutropenic by intraperitoneal (i.p.) injection of cyclophosphamide (CY) (Sigma) daily for 3 consecutive days at a dosage of $100 \mathrm{mg} / \mathrm{kg}$ body weight. Mice were monitored at designated days after the first CY injection for WBC counts by using a hemocytometer. Mice were then infected with $0.1 \mathrm{~mL}$ of $5 \times 10^{4}$ colony forming unit (CFU)/mL cells of $C$. albicans $11 \#$ per mouse in warmed saline $\left(35^{\circ} \mathrm{C}\right.$ ) by the lateral tail vein on day 3 after pretreatment with $\mathrm{CY}$. Berberine $(1 \mathrm{mg} / \mathrm{kg})$ and fluconazole $(0.5 \mathrm{mg} / \mathrm{kg})$ independently are administered by i.p. $6 \mathrm{~h}$ post-infection and once daily thereafter for $3 \mathrm{~d}$; and $0.1 \mathrm{~mL}$ of diluent (Dulbecco's phosphate-buffered saline, DPBS) by the same route as the placebo regimens. Data were averaged from three experiments.

\subsection{Cytotoxicity evaluation using 3-(4,5-dimethylthiazol-2-yl)-2,5- diphenyltetrazolium bromide (MTT) assay}

The protocol was modified from previous version [24]. Briefly, the testing cells were seeded in a 96-well flat-bottom microtiter 
plate with $1 \times 10^{4}$ cells/well and allowed to adhere for $24 \mathrm{~h}$ at $37{ }^{\circ} \mathrm{C}$ in a $\mathrm{CO}_{2}$ incubator. Cells were gently washed with fresh medium. Cells were then treated with various concentrations of the target compounds for $24 \mathrm{~h}$ in the same cultivation condition. Cells are gently washed with the fresh medium again. Subsequently, $10 \mu \mathrm{L}$ of MTT working solution ( $5 \mathrm{mg} / \mathrm{mL}$ in phosphate buffer solution) was added to each well and the plate is incubated for $4 \mathrm{~h}$ at $37{ }^{\circ} \mathrm{C}$ in a $\mathrm{CO}_{2}$ incubator. The medium was then aspirated, and the formed formazan crystals were solubilized by adding $50 \mu \mathrm{L}$ of dimethyl sulphoxide (DMSO) per well for $30 \mathrm{~min}$ at $37^{\circ} \mathrm{C}$ in a $\mathrm{CO}_{2}$ incubator. Finally, the intensity of the dissolved formazan crystals (purple color) was quantified using the enzyme-linked immuno sorbent assay (ELISA) plate reader at $540 \mathrm{~nm}$.

\section{Results}

\subsection{Berberine susceptibility is inversely correlated with MDR1 expression in C. albicans}

To search for natural products that can utilize the drug excretion transporter for importation and accumulation, 29 clinical $C$. albicans isolates were used (Table S1 online) to screen our natural products collection of $\sim 3800$ pure compounds and $\sim 100,000$ crude extracts. Many of these clinical isolates overexpress drug excretion transporters, which results in fluconazole resistance (Fig. 1a). However, we observed a cluster of one set of the fluconazole-resistant $C$. albicans isolates with MDR1 overexpression that showed hypersensitivity to berberine (boxed panel of Fig. 1a). Next, we investigated the relationship between Mdr1p overexpression and the hypersensitivity of berberine. Another set of $C$. albicans strains with different expression levels of Mdr1p were used, namely, CaS, CaR, CaDEL, and CaCOM (Table S1 online). CaS, isolated from an AIDS patient $\mathrm{G}$, was proven to be the original fluconazole-susceptible strain with basal Mdr1p expression, while CaR, isolated from the same patient after two years of treatment with fluconazole [25], was highly resistant to fluconazole, and the dominant contributor of fluconazole resistance was Mdr1p overexpression [7,26] (Fig. S1 online). CaDEL was constructed by MDR1 deletion of CaR [26], and CaCOM was constructed by MDR1 reconstitution into CaDEL [7]. MDR1 expression levels of these four strains were confirmed by quantitative real-time PCR (Fig. 1b), and the Mdr1 protein abundance was confirmed by Western blotting [7]. From the spot assay results (Fig. 1c), the growth of those strains with high levels of Mdr1p ( $\mathrm{CaR}$ and CaCOM) were inhibited by berberine, while they were uniformly resistant to fluconazole (red boxed panel of Fig. 1c). In contrast, CaS and CaDEL, the two strains with basal expression levels of Mdr1p, showed resistance to berberine but were susceptible to fluconazole (Fig. 1c). These results suggested that berberine has a "selectively eliminate the Mdr1p overex-

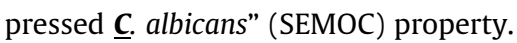

We speculated that berberine would not be the only natural compound with SEMOC. Besides berberine, other compounds, like jatrorrhizine, proflavine, palmatine, and BQM [27] which have higher activity against drug-resistant $C$. albicans with Mdr1p overexpression over wild type $C$. albicans were also identified from our screening (Fig. S2 online).

\subsection{Berberine could specifically be accumulated in Mdr1p overexpressed $C$. albicans cells}

Next, we sought to understand the biological mechanism underlying SEMOC property. As berberine has fluorescence emission at $520 \mathrm{~nm}$ by $360 \mathrm{~nm}$ excitation, intracellular berberine accumulation can be quantitated by fluorescence readout. We measured the rate of accumulation and release of intracellular berberine in all four strains: CaR, CaS, CaDEL, and CaCOM, it showed a progressive and consistent increase in berberine accumulation throughout a 90-min incubation period (left panel of Fig. 1d). The amount of berberine in strain CaR is approximately three times as much as that observed in CaS and CaDEL. We observed that the rate of berberine uptake in Mdr1p overexpressed strains exceeded the rate of release (Fig. 1d), leading to a net accumulation of berberine in CaR and CaCOM strains. This observation suggested that overexpressed Mdr1p might serve as an importer of berberine into C. albicans cells.

To confirm this possibility, we further tested whether the accumulation of berberine was dependent on a proton gradient, as Mdr1p utilizes the proton gradient across the cytoplasmic membrane as its energy source for transportation [4,7]. Carbonyl cyanide $\mathrm{m}$-chlorophenylhydrazone (CCCP) was used to uncouple the proton gradient. Berberine accumulation indeed decreased in Mdr1p-(over)expressed strains after CCCP treatment (Fig. 1e). This data not only confirmed the proton gradient played an important role in berberine accumulation but also indicated that the effects of Mdr1p-overexpression in berberine accumulation.

Due to the $\mathrm{drug} / \mathrm{H}^{+}$antiporter property of $\mathrm{Mdr} 1 \mathrm{p}$, we hypothesized that an alkaline extracellular environment might switch Mdr1p from a drug efflux protein into a drug importer. Thus, we evaluated the extracellular $\mathrm{pH}$ effect on berberine accumulation. We observed that an increased extracellular $\mathrm{pH}$ (reduced extracellular $\mathrm{H}^{+}$concentration) promoted berberine accumulation in strains with a high level of Mdr1p (Fig. 1f).

\subsection{Intracellular berberine causes mitochondrial dysfunctions}

Then we asked how intracellular berberine inhibits the growth of $C$. albicans. We reasoned that a comparison of the intrinsic differences of response-to-berberine-treatment between $\mathrm{CaS}$ and $\mathrm{CaR}$ might reveal the targets of berberine. We analyzed the transcriptomes of $\mathrm{CaS}$ and CaR with and without berberine treatment, finding that a total of 182 genes were upregulated in CaR (cut-off $\geq$ 2.0 -fold, $P<0.05$ and FDR $<0.2$ ) (Fig. 2a), especially genes encoding oxidoreductases (21.7\%, GOID: $16491, P$ value $5.41 \times 10^{-7}$ ) such as the aldo-keto reductase family, IFD6 and CSH1. To further narrow down the cellular pathways affected by berberine in $C$. albicans, we performed Gene Set Enrichment Analysis (GSEA), and the

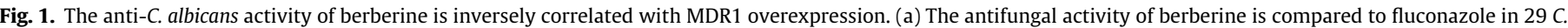

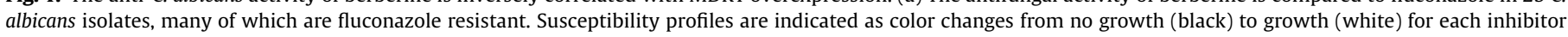

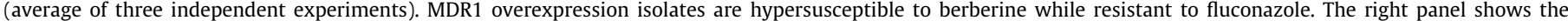

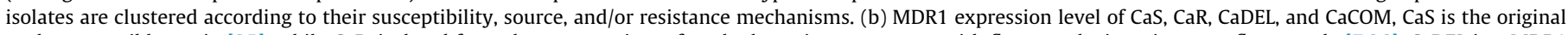

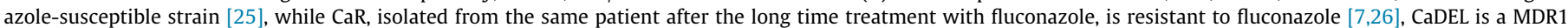

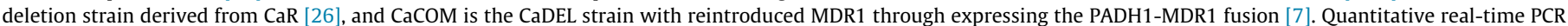

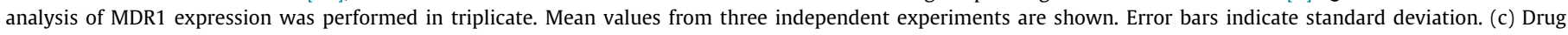

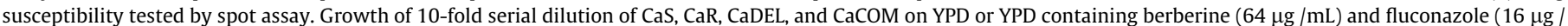

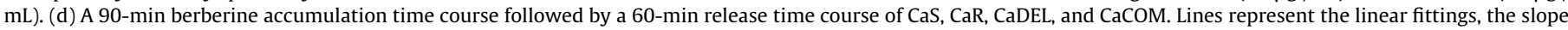

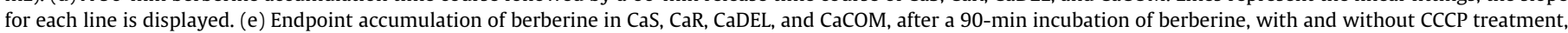
respectively. A two-tailed test is used for statistical analysis, ${ }^{* *} P<0.01$. (f) Extracellular $\mathrm{pH}$ affected the berberine accumulation in CaS, CaR, CaDEL, and CaCOM.
} 
(a)

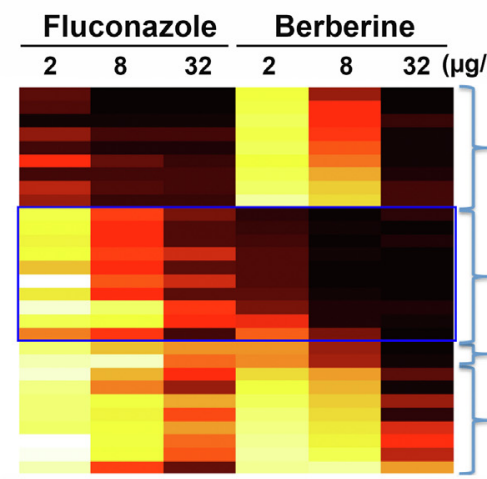

\section{Relative growth}

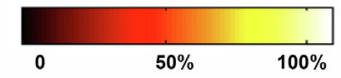

Fluconazole sensitive isolates

Fluconazole resistant isolates MDR1 overexpression

Fluconazole resistant isolates MDR1/CDR1 overexpression

Fluconazole resistant isolates CDR1/CDR2 overexpression (b)

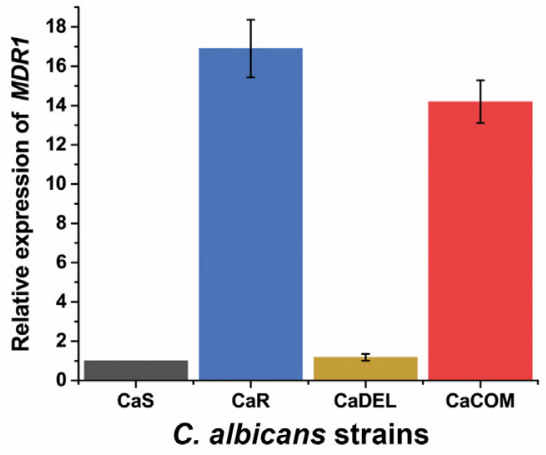

(c)

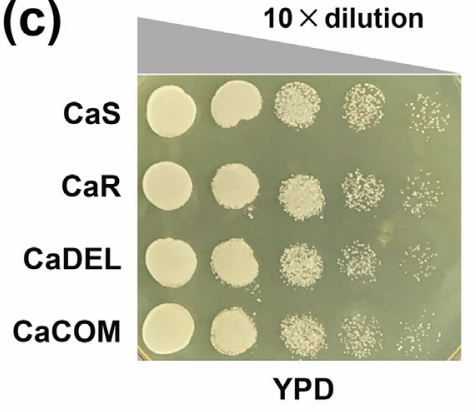

(d)

$10 \times$ dilution

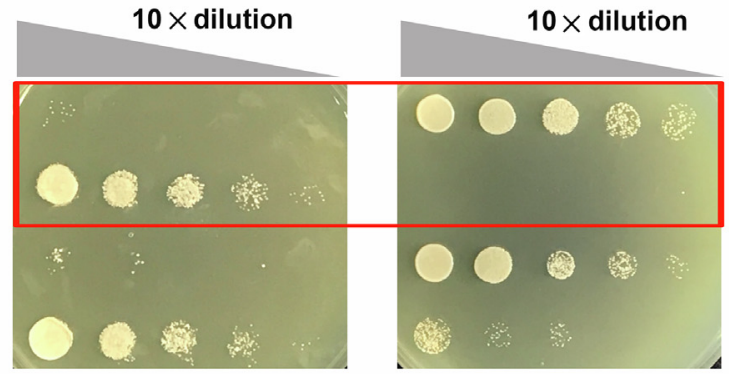

Fluconazole $16(\mu \mathrm{g} / \mathrm{mL})$

Berberine $64(\mu \mathrm{g} / \mathrm{mL})$

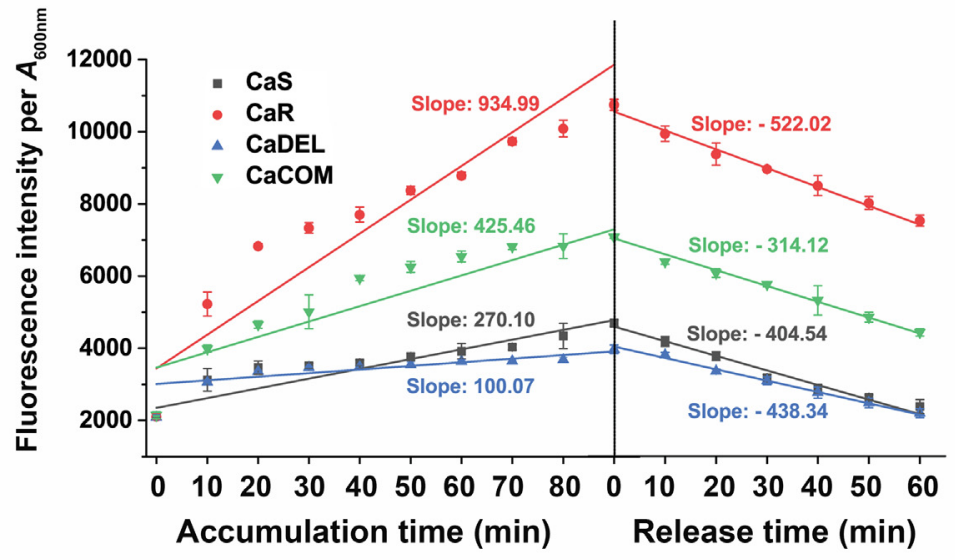

(e)

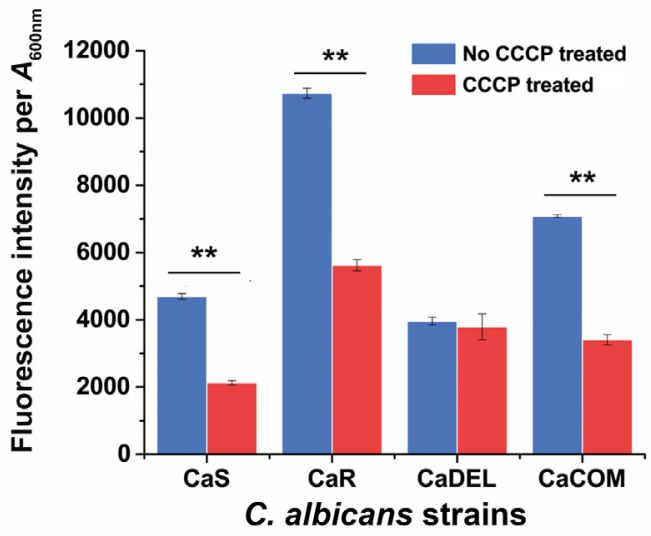

(f)

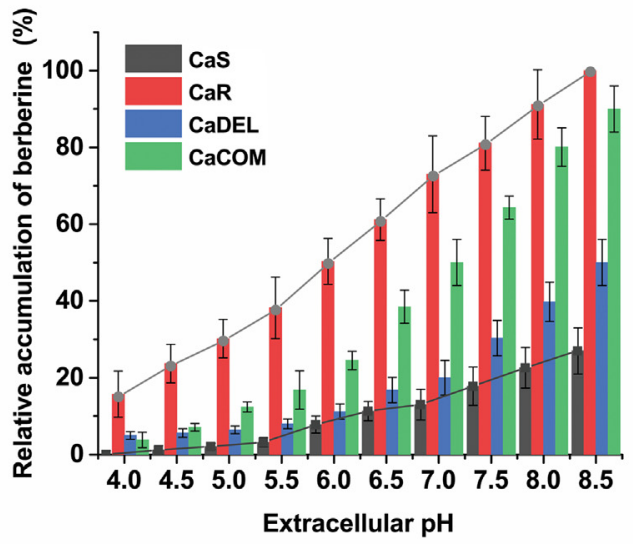




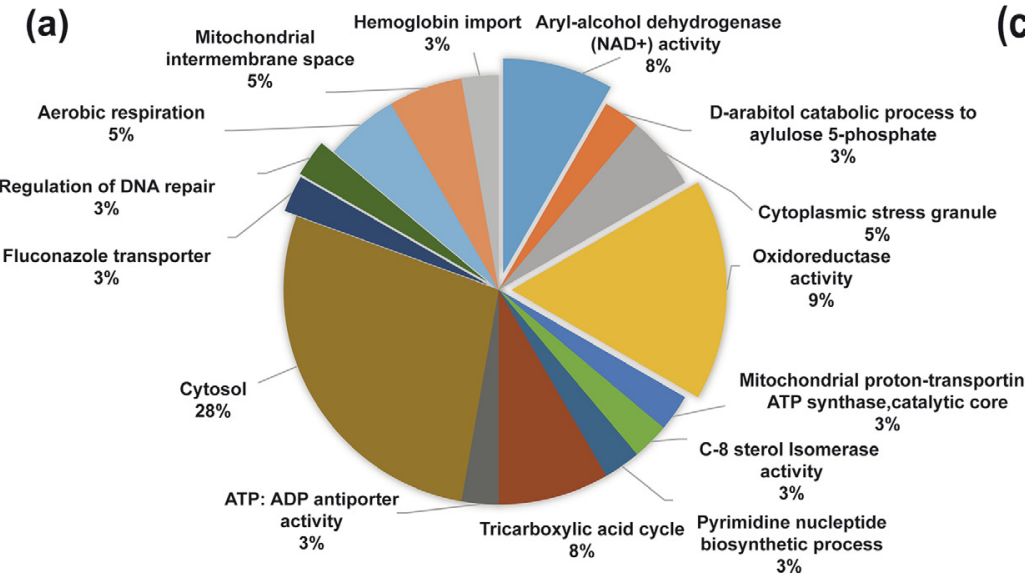

(b)

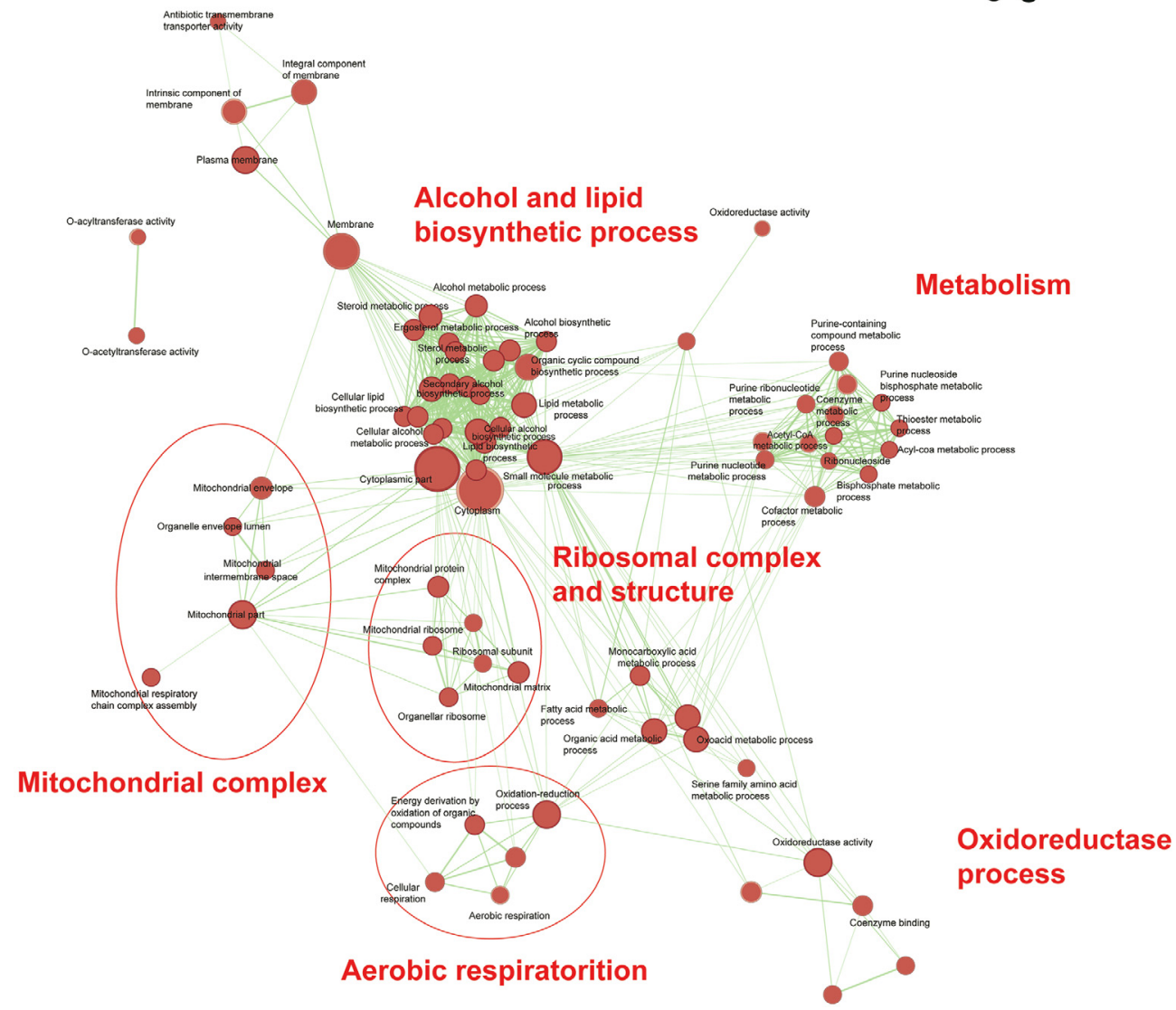

(c)

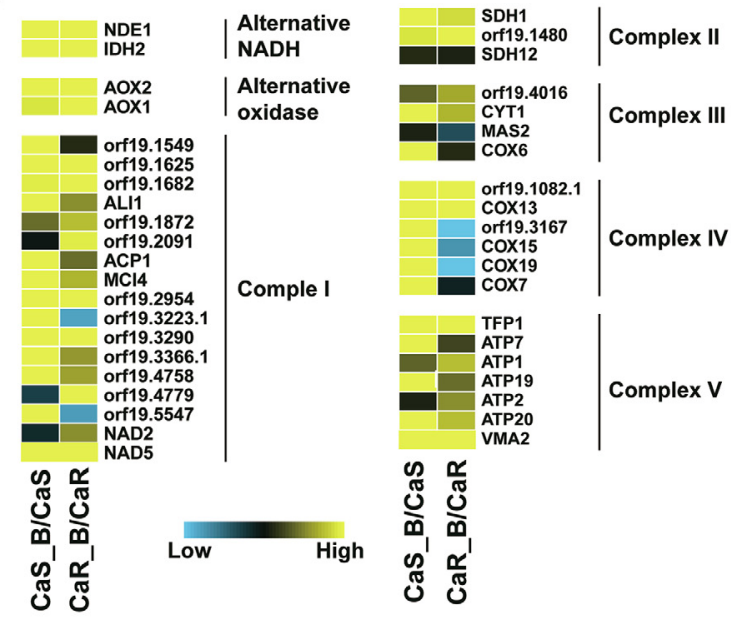

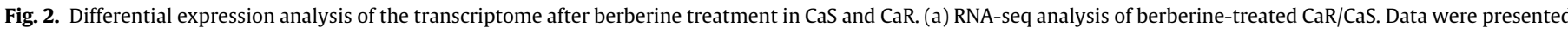

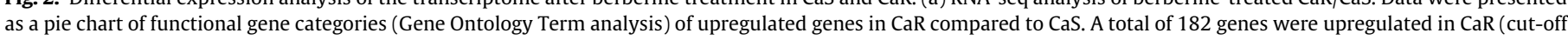

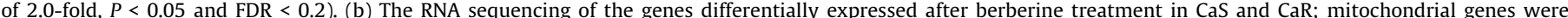

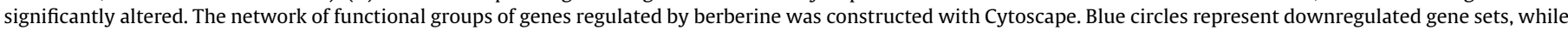

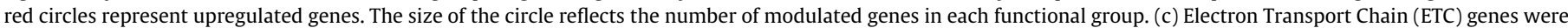

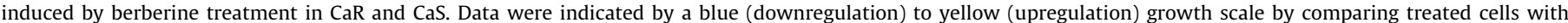

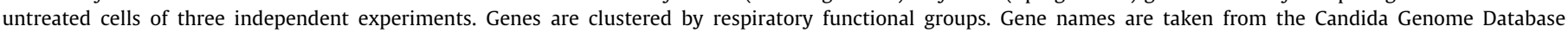

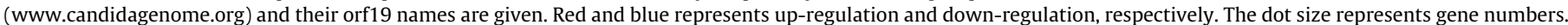

ranked gene lists from the transcript profiles were compiled according to the change in their expression to a predefined database of 8123 gene sets [28]. Significantly enriched gene sets were further visualized using Cytoscape. We observed that the expression of mitochondrial function/aerobic respiration related genes was significantly upregulated after berberine treatment (Fig. 2b, c). These results suggested that berberine impacted mitochondrial function.

To test this hypothesis, we first confirmed that berberine can accumulate in the mitochondria and as expected, mitochondria of CaR accumulate a higher level of berberine than that of $\mathrm{CaS}$ (Fig. 3a). Berberine also exhibited a greater inhibition on non- 


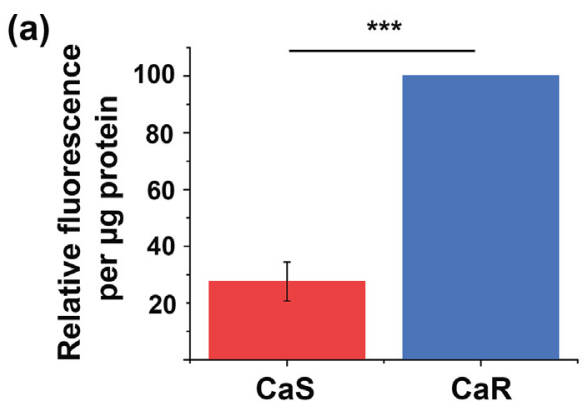

(b)

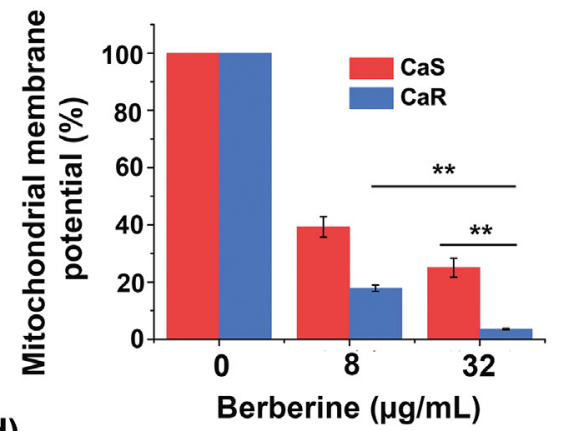

(d)

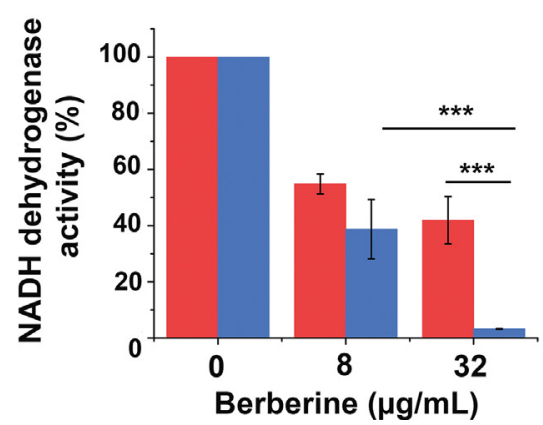

(c)

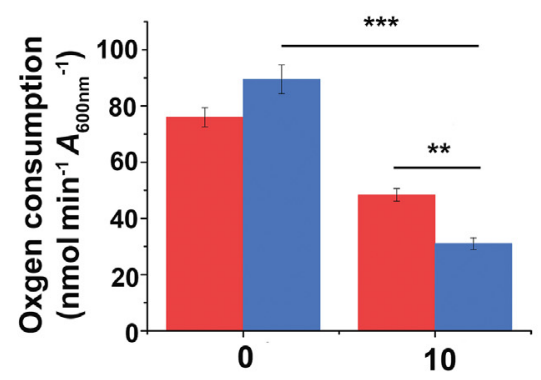

(e)

Berberine $(\mu \mathrm{g} / \mathrm{mL})$

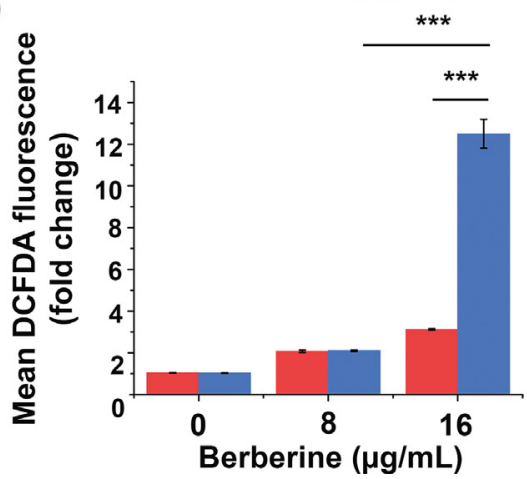

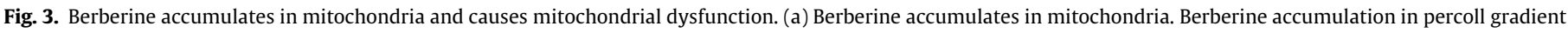

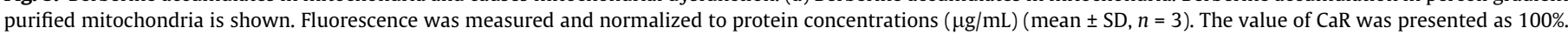

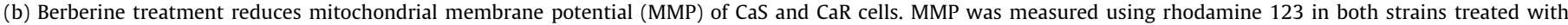

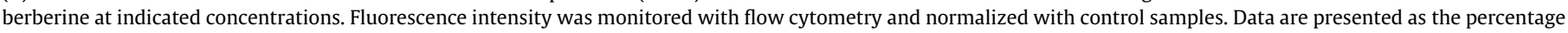

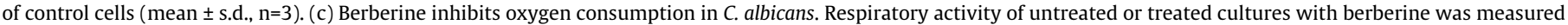

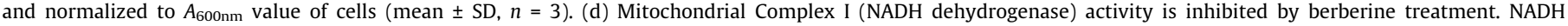

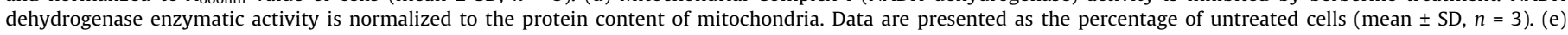

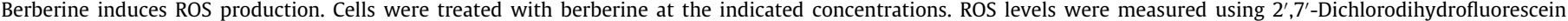
diacetate (DCFDA) by flow cytometry and shown as fold-changes (mean $\pm \mathrm{SD}, n=3$ ). A two-tailed test is used for statistical analysis, ${ }^{* *} P<0.01$; ${ }^{* * *} P<0.001$

fermentable carbon sources compared to that on glucose, which possibly indicated that respiration was compromised during berberine treatment (Fig. S3 online). Besides, important parameters reflecting fungal mitochondrial function were examined. Berberine was found to significantly impair mitochondrial membrane potential (Figs. 3b and S4 online), and oxygen consumption (Fig. 3c). Also, after berberine treatment, the activity of the Complex I (NADH dehydrogenase) was sharply reduced (Fig. 3d). In addition, $N D H 51$, encoding the mitochondrial Complex I 51-kD subunit of the NADH dehydrogenase protein Ndh51p, was downregulated by 29.9 folds after berberine treatment. To validate Ndh51p as one potential target of berberine, haploinsufficiency (HI) was examined, since the organism is diploid and heterozygote strains lacking one allele usually demonstrate HI. In this regard, the heterozygote $\mathrm{NDH} 51$ mutant demonstrated an HI phenotype that was more susceptible to berberine whereas $n d h 51 \Delta$ was more tolerant compared with the wild type due to the lack of target gene (Fig. S5 online). All of these results indicate that berberine interacts with and causes mitochondria dysfunction, which typically stimulates ROS production.

Consistent with this hypothesis, we found that berberine treatment indeed induced ROS production (Figs. 3e and S6 online). In contrast, the addition of antioxidant agents such as ascorbic acid and N-acetyl cysteine (NAC) abrogated the inhibitory effects of berberine (Fig. S7 online). Collectively, this data reveals that berberine activity is related to mitochondrial dysfunction in C. albicans. However, we cannot exclude the possibility that berberine, like many other drugs, has multiple targets, given the fact that berberine exhibits a wide spectrum of biological activities.

3.4. Berberine has a high potential to be an antifungal agent against multidrug-resistant invasive fungal pathogens

Besides the novel observation of SEMOC property. We next extensively evaluated the antifungal activity of berberine against several other wild types of common fungal pathogens. We saw that 
Table 1

Berberine is active against various fungal pathogens with low toxicity to human cells.

\begin{tabular}{|c|c|c|c|}
\hline \multirow[t]{2}{*}{ Species } & \multicolumn{3}{|c|}{$\operatorname{MIC}(\mu \mathrm{g} / \mathrm{mL})^{\mathrm{a}}$} \\
\hline & Fluconazole & Itraconazole & Berberine \\
\hline C. albicans (SC5314) & 0.25 & & 8 \\
\hline C. guilliermondii & 2 & & 16 \\
\hline C. glabrata & 2 & & 1 \\
\hline C. tropicalis & 0.5 & & 2 \\
\hline C. parapsilosis & 1 & & 16 \\
\hline C. lusitaniae & 2 & & 4 \\
\hline C. apicola & 0.25 & & 4 \\
\hline C. krusei & 32 & & 4 \\
\hline C. neoformans (H99) & 4 & & 4 \\
\hline C. neoformans (JEC-21) & 2 & & 2 \\
\hline A. fumigatus (H11-20) & & 0.5 & 4 \\
\hline A. fumigatus (AF293) & & 0.5 & 4 \\
\hline MDR A. fumigatus RIT2 & & $>100$ & 4 \\
\hline MDR A. fumigatus RIT3 & & $>100$ & 4 \\
\hline MDR A. fumigatus RIT5 & & $>100$ & 4 \\
\hline MDR A. fumigatus RIT8 & & $>100$ & 8 \\
\hline MDR A. fumigatus RIT10 & & $>100$ & 4 \\
\hline MDR A. fumigatus RIT11 & & $>100$ & 4 \\
\hline MDR A. fumigatus RIT14 & & $>100$ & 4 \\
\hline HepG2 liver cell & & & $>90$ \\
\hline $\mathrm{NIH} / 3 \mathrm{~T} 3$ fibroblast cell & & & $>100$ \\
\hline 293T kidney cell & & & $>80$ \\
\hline
\end{tabular}

${ }^{a}$ MIC: minimum inhibitory concentration.

berberine was active against most of those fungal pathogens at relatively low concentrations (from 1 to $16 \mu \mathrm{g} / \mathrm{mL}$ ) (Table 1 ). Remarkably, we also observed that berberine strongly inhibited MDR Aspergillus fumigatus (Table 1), the chief cause of invasive aspergillosis (IA). Patients with IA have a mortality rate higher than $90 \%$ [29]. However, berberine only showed negligible cytotoxicity against several human cell lines (Table 1 ).

To further evaluate berberine's potential as an anti-MDR C. albicans agent, we tested the antifungal activity of berberine on a set of clinical C. albicans isolates, $1 \#, 4 \#, 7 \#$, and 11\#. They were sequentially isolated from an HIV patient who was given an increasing dose of fluconazole during a two years period [30]. As a result, strains $4 \#, 7 \#$, and 11\# displayed fluconazole resistance. Interestingly, like CaS and CaR strains, 4\#, 7\#, and 11\# strains were also found to have MDR1 overexpression (by quantitative real-time PCR) (Fig. 4a). Consistent with our previous observation, these naturally acquired drug-resistant strains 4\#, 7\#, and 11\# showed enhanced susceptibility to berberine over strain 1\# (the parental strain) (Fig. 4b). Again, our results demonstrate that the drugresistant $C$. albicans due to Mdr1p overexpression could be specifically inhibited by berberine.

Candidiasis is often fatal in immunocompromised patients. For this reason, we tested the efficacy of berberine in an immunocompromised animal model of candidiasis. For this purpose, we established an immunocompromised mouse model by i.p. injection of cyclophosphamide (CY) at a dose of $100 \mathrm{mg} / \mathrm{kg}$ (body weight) once a day for three consecutive days to specific pathogen-free female ICR mice as described previously [15]. An inoculum $(0.1 \mathrm{~mL})$ of $5 \times 10^{4} \mathrm{CFU} / \mathrm{mL}$ cells of $C$. albicans strain $11 \#$ (fluconazoleresistant, while berberine sensitive, MDR1 overexpression) per mouse killed all mice within 7-8 d (mean survival time, MST was $4.1 \pm 0.5 \mathrm{~d}$ ). Berberine and fluconazole (as a control) were administered by i.p. $6 \mathrm{~h}$ post-infection and once a day thereafter for $3 \mathrm{~d}$. A control group of 20 mice received $0.1 \mathrm{~mL}$ of diluent DPBS by the same route as the placebo regimens. We saw that berberine treatment dramatically prolonged the MST of those infected mice $(P<0.01)$, while due to the MDR1 overexpression causing multidrug resistance, fluconazole failed to save the infected mice (Fig. 4c). From this data, we could conclude that berberine has a very good potential being an antifungal agent against multidrugresistant $C$. albicans due to MDR1 overexpression.

\subsection{Investigation of acquired berberine resistance from the berberine sensitive strain $\mathrm{CaR}$}

To investigate if berberine resistant phenotype would be developed in the berberine sensitive strain CaR over the usage of berberine, we used a rapid assay by plating large numbers of CaR cells onto YPD plates containing a high concentration of berberine $(100 \mu \mathrm{g} / \mathrm{mL})$. After $3-5 \mathrm{~d}$ of incubation at $30^{\circ} \mathrm{C}$, some colonies could be seen from the plate. As described previously, only colonies with sizes $\geq 1.6 \mathrm{~mm}^{2}$ had acquired robust, reproducible resistance [31]. Therefore, we randomly picked 10 clones with sizes larger than $\geq 1.6 \mathrm{~mm}^{2}$, upon MIC test, we found that the MIC of berberine had increased about 50 -fold $(100 \mu \mathrm{g} / \mathrm{mL})$ in the 8 out 10 picked colonies (Fig. S8 online). We named this group of berberine resistant strains CaRm. As anticipated, CaRm strains become susceptible to fluconazole again with a MIC of $0.39 \mu \mathrm{g} / \mathrm{mL}$ (Fig. S8 online). We also investigated the MDR1 expression levels of CaRm with qRT-PCR. Results showed that MDR1 expression in CaRm decreased more than 12 -fold compared to CaR. It is consistent with our findings that the susceptibility of $C$. albicans strains to berberine is inversely correlated with MDR1 expression levels. As a consequence of less Mdr1p, this acquired berberine resistance in CaR results in fluconazole sensitization, which we believe could be a good sign for the clinic.

\section{Discussion and conclusion}

Multidrug resistance is a worldwide problem that is exacerbated by the shrinking pipeline of new antimicrobial agents. Fungal pathogens adopt intricate strategies to avoid the lethal effects of antibiotics [2,32], one of which is overexpression of efflux pump Mdr1p [7]. Here we investigated whether Mdr1p, instead of promoting resistance, could be co-opted to promote selective killing of resistant $C$. albicans instead. The enhanced antifungal activity results from the increased intracellular accumulation of berberine in MDR1 overexpressed C. albicans. Intriguingly, berberine is reported to accumulate in the rhizome of Coptis japonica via an ABC transporter (Cjmdr1p) [33], and it can be excreted by some bacterial multidrug excretion transporters, thereby rendering it relatively ineffective as a therapeutic antibacterial agent [34]. Though Mdr1p in C. albicans, Cjmdr1p in Coptis japonica and NorA $[34,35]$ in bacteria do not share structure similarities, they can serve as the channels for berberine, either importing or exporting into cells, which indicated that berberine could be transported by many different types of transporters. The findings reported here may represent a novel strategy to overcome MDR, not only in fungal pathogens but also in bacterial pathogens or even other human diseases such as drug-resistant cancers. Moreover, we suggest the potential of mitochondria to be a target for new antifungal drug discovery, given that fungal mitochondria have proteins that differ from human mitochondria. Supporting this hypothesis, the deletion of genes encoding these proteins causes cell dysfunction $[21,36,37]$. Given the significant differences between human cell mitochondria and C. albican mitochondria [38], targeting mitochondria might be one of the reasons that berberine showed selective fungal cytotoxicity over the selected human cells of HepG2, $\mathrm{NIH} / 3 \mathrm{~T} 3$, and 293T.

\section{Conflict of interest}

The authors declare that they have no conflict of interest. 


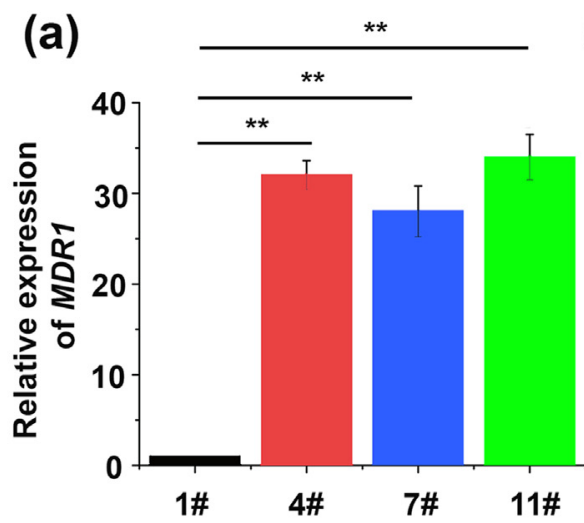

C. albicans strains (b)

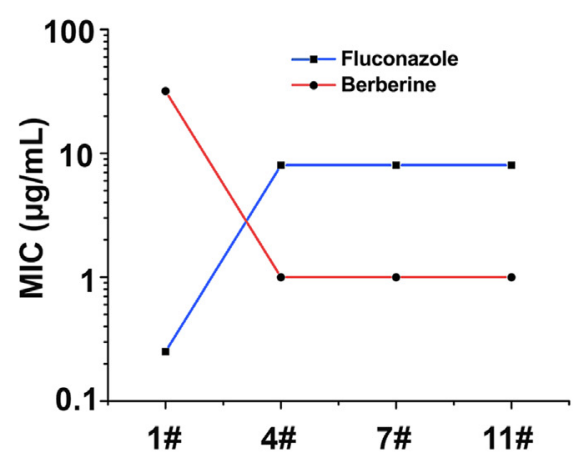

C. albicans strains

(c)

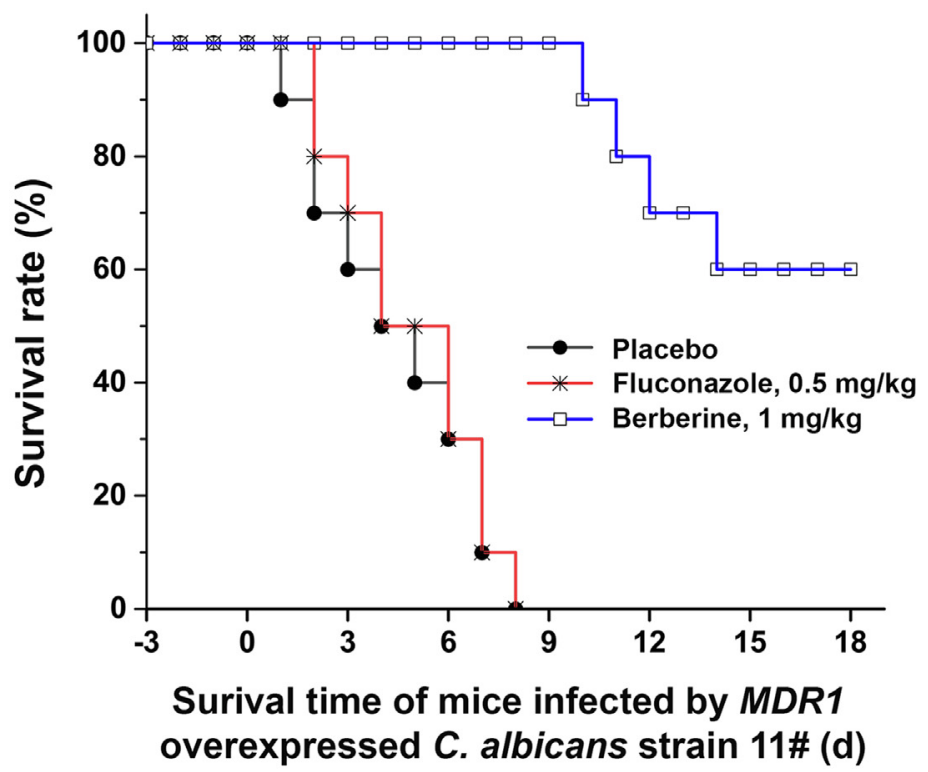

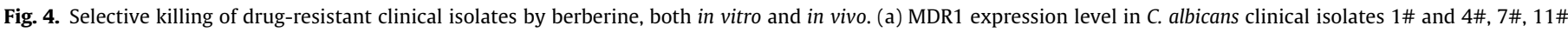

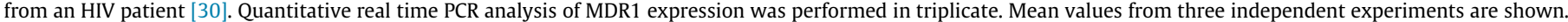

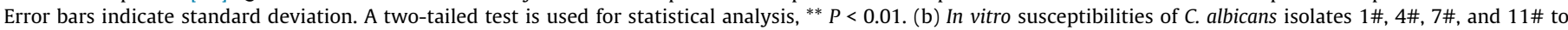

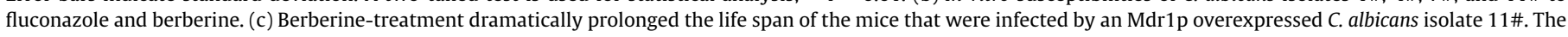
total observation period is 21 days.

\section{Acknowledgments}

We thank Joachim Morschhäuser, Dominique Sanglard, and Theodore White for kindly providing drug-resistant clinical fungal isolates. We thank Haian Fu, Bruce Alberts, Rong An, Elizabeth Ashforth, and Glen Bulmer for their critical reading of the manuscript and helpful discussions. This work was supported by the National Key Research and Development Program of China (2020YFA0907800), the National Natural Science Foundation of China (31720103901), the "111" Project of China (B18022), the Fundamental Research Funds for the Central Universities (22221818014S), the Open Project Funding of the State Key Laboratory of Bioreactor Engineering, the Shandong Taishan Scholar Award, and the Novo Nordisk Foundation (NNF10CC1016517).

\section{Author contributions}

Yaojun Tong, Nuo Sun, Fan Bai, and Lixin Zhang conceived and designed the experiments. Yaojun Tong, Jingyu Zhang, Nuo Sun, Xiang-Ming Wang, Qi Wei, Yu Zhang, Yingying Pu, Huanqin Dai,
Biao Ren, Gang Pei, Fuhang Song, Guoliang Zhu, Xinye Wang, Xuekui Xia, Xiangyin Chen, and Lan Jiang performed all experiments. Nuo Sun, Yaojun Tong, Lixin Zhang, Richard Calderone, Buchang Zhang, Ren Huang, Xueting Liu, Yuanying Jiang, Gil Alterovitz, and Fan Bai analyzed the data. Yaojun Tong, Nuo Sun, Fan Bai, and Lixin Zhang wrote the manuscript. Yaojun Tong, Xiang-Ming Wang, Fan Bai, Lixin Zhang, Liming Ouyang, Shenlin Wang, and Ning Xie revised the manuscript.

\section{Appendix A. Supplementary materials}

Supplementary materials to this article can be found online at https://doi.org/10.1016/j.scib.2020.12.035.

\section{References}

[1] Gow NAR, van de Veerdonk FL, Brown AJP, et al. Candida albicans morphogenesis and host defence: discriminating invasion from colonization. Nat Rev Microbiol 2012;10:112-22.

[2] Cowen LE. The evolution of fungal drug resistance: modulating the trajectory from genotype to phenotype. Nat Rev Microbiol 2008;6:187-98. 
[3] Holmes AR, Lin Y-H, Niimi K, et al. ABC transporter Cdr1p contributes more than $\mathrm{Cdr} 2 \mathrm{p}$ does to fluconazole efflux in fluconazole-resistant Candida albicans clinical isolates. Antimicrob Agents Chemother 2008;52:3851-62.

[4] Pasrija R, Banerjee D, Prasad R. Structure and function analysis of CaMdr1p, a major facilitator superfamily antifungal efflux transporter protein of Candida albicans: identification of amino acid residues critical for drug $/ \mathrm{H}^{+}$transport. Eukaryot Cell 2007;6:443-53.

[5] Yan N. Structural advances for the major facilitator superfamily (MFS) transporters. Trends Biochem Sci 2013;38:151-9.

[6] Yan N. Structural biology of the major facilitator superfamily transporters. Annu Rev Biophys 2015;44:257-83.

[7] Hiller D, Sanglard D, Morschhäuser J. Overexpression of the MDR1 gene is sufficient to confer increased resistance to toxic compounds in Candida albicans. Antimicrob Agents Chemother 2006;50:1365-71.

[8] Sack RB, Froehlich JL. Berberine inhibits intestinal secretory response of Vibrio cholerae and Escherichia coli enterotoxins. Infect Immun 1982;35:471-5.

[9] Meeran SM, Katiyar S, Katiyar SK. Berberine-induced apoptosis in human prostate cancer cells is initiated by reactive oxygen species generation. Toxicol Appl Pharmacol 2008:229:33-43.

[10] Kuo C-L, Chi C-W, Liu T-Y. The anti-inflammatory potential of berberine in vitro and in vivo. Cancer Lett 2004;203:127-37.

[11] Yin J, Xing H, Ye J. Efficacy of berberine in patients with type 2 diabetes mellitus. Metabolism 2008;57:712-7.

[12] Kong W, Wei J, Abidi P, et al. Berberine is a novel cholesterol-lowering drug working through a unique mechanism distinct from statins. Nat Med 2004:10:1344-51.

[13] Pereira GC, Branco AF, Matos JAC, et al. Mitochondrially targeted effects of berberine [Natural Yellow 18, 5,6-dihydro-9,10-dimethoxybenzo(g)-1,3benzodioxolo(5,6-a) quinolizinium] on K1735-M2 mouse melanoma cells: comparison with direct effects on isolated mitochondrial fractions. J Pharmacol Exp Ther 2007;323:636-49.

[14] Li D, Calderone R. Exploiting mitochondria as targets for the development of new antifungals. Virulence 2017;8:159-68.

[15] Zhang L, Yan K, Zhang Y, et al. High-throughput synergy screening identifies microbial metabolites as combination agents for the treatment of fungal infections. Proc Natl Acad Sci USA 2007;104:4606-11.

[16] Clinical and Laboratory Standards Institute. Reference method for broth dilution antifungal susceptibility testing of yeasts; Approved standard, 3rd ed, CLSI document M27-A3. Wayne, PA: National Committee for Clinical Laboratory Standards; 2008.

[17] Sanglard D, Ischer F, Parkinson T, et al. Candida albicans mutations in the ergosterol biosynthetic pathway and resistance to several antifungal agents. Antimicrob Agents Chemother 2003;47:2404-12.

[18] Trapnell C, Pachter L, Salzberg SL. Tophat: discovering splice junctions with RNA-seq. Bioinformatics 2009;25:1105-11.

[19] Anders S, Pyl PT, Huber W. HTSeq-a Python framework to work with highthroughput sequencing data. Bioinformatics 2015;31:166-9.

[20] Love MI, Huber W, Anders S. Moderated estimation of fold change and dispersion for RNA-seq data with DESeq2. Genome Biol 2014;15:550.

[21] Li D, Chen H, Florentino A, et al. Enzymatic dysfunction of mitochondrial complex I of the Candida albicans goa1 mutant is associated with increased reactive oxidants and cell death. Eukaryot Cell 2011;10:672-82.

[22] Ferlini C, Scambia G. Assay for apoptosis using the mitochondrial probes, Rhodamine123 and 10- $\mathrm{N}$-nonyl acridine orange. Nat Protoc 2007:2:3111-4.

[23] Xu Z, Zhang L-X, Zhang J-D, et al. cDNA microarray analysis of differential gene expression and regulation in clinically drug-resistant isolates of Candida albicans from bone marrow transplanted patients. Int J Med Microbiol 2006;296:421-34.

[24] Bahuguna A, Khan I, Bajpai VK, et al. MTT assay to evaluate the cytotoxic potential of a drug. Bangladesh J Pharmacol 2017;12:115-8.

[25] Franz R, Kelly SL, Lamb DC, et al. Multiple molecular mechanisms contribute to a stepwise development of fluconazole resistance in clinical Candida albicans strains. Antimicrob Agents Chemother 1998;42:3065-72.

[26] Wirsching S, Michel S, Morschhauser J. Targeted gene disruption in Candida albicans wild-type strains: the role of the MDR1 gene in fluconazole resistance of clinical Candida albicans isolates. Mol Microbiol 2000;36:856-65.

[27] Sun N, Li D, Fonzi W, et al. Multidrug-resistant transporter Mdr1p-mediated uptake of a novel antifungal compound. Antimicrob Agents Chemother 2013;57:5931-9.

[28] Uwamahoro N, Qu Y, Jelicic B, et al. The functions of mediator in Candida albicans support a role in shaping species-specific gene expression. PLoS Genet 2012;8:e1002613.

[29] Nascimento AM, Goldman GH, Park S, et al. Multiple resistance mechanisms among Aspergillus fumigatus mutants with high-level resistance to itraconazole. Antimicrob Agents Chemother 2003;47:1719-26.

[30] White TC. Increased mRNA levels of ERG16, CDR, and MDR1 correlate with increases in azole resistance in Candida albicans isolates from a patient infected with human immunodeficiency virus. Antimicrob Agents Chemother 1997;41:1482-7.

[31] Cowen LE. Hsp90 potentiates the rapid evolution of new traits: drug resistance in diverse fungi. Science 2005;309:2185-9.

[32] Anderson JB. Evolution of antifungal-drug resistance: mechanisms and pathogen fitness. Nat Rev Microbiol 2005;3:547-56.

[33] Shitan N, Bazin I, Dan K, et al. Involvement of CjMDR1, a plant multidrugresistance-type ATP-binding cassette protein, in alkaloid transport in Coptis japonica. Proc Natl Acad Sci USA 2003;100:751-6.
[34] Stermitz FR, Lorenz P, Tawara JN, et al. Synergy in a medicinal plant: antimicrobial action of berberine potentiated by 5'-methoxyhydnocarpin, a multidrug pump inhibitor. Proc Natl Acad Sci USA 2000;97:1433-7.

[35] Ball AR, Casadei G, Samosorn S, et al. Conjugating berberine to a multidrug efflux pump inhibitor creates an effective antimicrobial. ACS Chem Biol 2006; 1:594-600.

[36] Shingu-Vazquez M, Traven A. Mitochondria and fungal pathogenesis: drug tolerance, virulence, and potential for antifungal therapy. Eukaryot Cell 2011:10:1376-83.

[37] Sun N, Fonzi W, Chen H, et al. Azole susceptibility and transcriptome profiling in Candida albicans mitochondrial electron transport chain complex I mutants. Antimicrob Agents Chemother 2013;57:532-42.

[38] Sun N, Parrish RS, Calderone RA, Fonzi WA. Unique, diverged, and conserved mitochondrial functions influencing Candida albicans respiration. mBio 2019; 10:e00300-19.

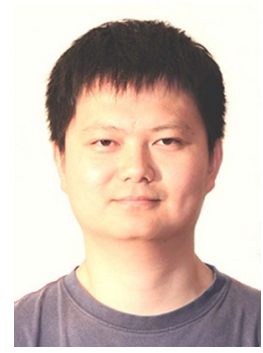

Yaojun Tong received his Ph.D. degree from the Institute of Microbiology, Chinese Academy of Sciences, then he joined the Novo Nordisk Foundation Center for Biosustainability, the Technical University of Denmark as a postdoc in 2013, and was promoted to a researcher in 2016. Currently, he is a tenure-track associate professor at Shanghai Jiao Tong University. His research focuses on synthetic biology.

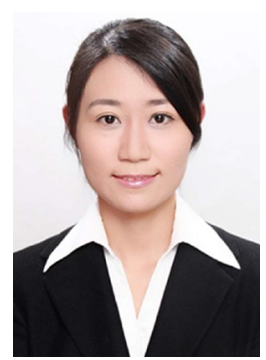

Jingyu Zhang received her Ph.D. degree in 2012 from the China Pharmaceutical University. Her current research interest focuses on mining of novel natural products from actinomycetes and deciphering their biosynthetic pathways.

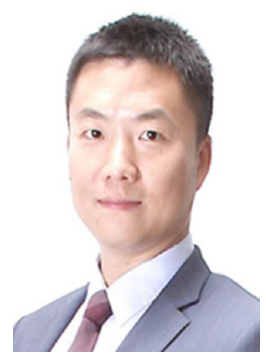

Nuo Sun obtained his Ph.D. degree from Georgetown University. His research interest focuses on investigating how altered mitochondrial function contributes to disease progression, and exploring effective interventions to counteract mitochondria-related diseases. He also seeks to elucidate molecular pathways regulating mitochondrial metabolism using cellular, genetic, and biochemical approaches.

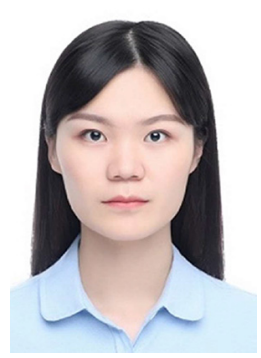

Xiang-Ming Wang received her bachelor's degree from Xiamen University in 2016 and is now a Ph.D. candidate at Prof. Bai's Lab, Biomedical Pioneering Innovation Center (BIOPIC), Peking University. Her research interest focuses on deciphering underlying biological mechnisms by using cellular, genetic, and biochemical approaches. 


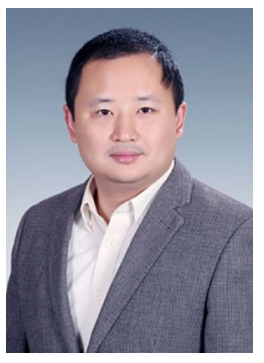

Fan Bai received his bachelor's degree (Physics) from Peking University in 2003 and Ph.D. degree (Biophysics) from the University of Oxford in 2008. After three years of postdoctoral training at the University of Oxford and Osaka University, he returned to China in 2011 and led his own research team at Peking University, Biomedical Pioneering Innovation Center (BIOPIC). His lab combines cutting-edge single-molecule fluorescence imaging and single cell sequencing to investigate problems at the frontier of biomedical research.

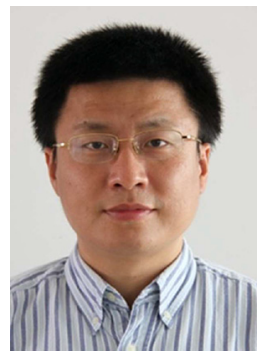

Lixin Zhang serves as the director of State Key Laboratory of Bioreactor Engineering, School of Biotechnology, East China University of Science and Technology. The long-term goal of his group is to discover and develop synergistic medicines from marine microbial natural products and increase their outputs through synthetic biology approaches. 